ISSN 0103-9954

\title{
CARACTERÍSTICAS DE FRUTOS E GERMINAÇÃO DE SEMENTES DE SEIS ESPÉCIES DE MYRTACEAE NATIVAS DO RIO GRANDE DO SUL
}

\section{FRUITS CHARACTERISTICS AND GERMINATION OF SEEDS OF SIX NATIVES MYRTACEAE SPECIES FROM RIO GRANDE DO SUL}

\author{
Cristina Magalhães Ribas dos Santos ${ }^{1}$ Alfredo Gui Ferreira ${ }^{2}$ Maria Estefânia Alves Áquila ${ }^{3}$ \\ RESUMO
}

A família Myrtaceae é muito bem representada na flora do estado do Rio Grande do Sul, região sul do Brasil. Frutos e sementes de seis espécies foram examinados quanto ao tamanho, cor, massa, teor de água. As espécies são: Acca sellowiana (Berg.) Burnet; Campomanesia guazumifolia (Camb.) Berg.; Campomanesia xanthocarpa Berg.; Eugenia rostrifolia Legr.; Myrcianthes pungens (Berg.) Legr. e Psidium cattleyanum Sabine. Avaliou-se o comportamento germinativo das sementes, tendo sido usada como substrato areia de rio autoclavada umedecida com água destilada, colocada em caixas gerbox $(11 \mathrm{x} 11 \mathrm{~cm})$ nas temperaturas constantes de $15,20,25$ ou $30^{\circ} \mathrm{C}$ ou na alternada de $15^{\circ} \mathrm{C}-30^{\circ} \mathrm{C}$, com 14 horas na temperatura mais alta. Os experimentos foram efetuados na presença e ausência de luz. Acca sellowiana, Myrcianthes pungens, Psidium cattleyanum mostraram sementes fotoblásticas positivas. Todas as espécies germinaram em noventa dias, exceto Campomanesia guazumifolia, que levou cerca de cento e cinqüenta dias. O conteúdo de água das sementes variou de $9 \%$ em Campomanesia guazumifolia até $68 \%$ em Myrcianthes pungens, ocorrendo sementes de intermediárias a recalcitrantes em relação à dessecação. Os embriões tipo eugenoide mostraram germinação criptocotiledonar, enquanto os embriões tipo mircióide e pimentóide apresentaram comportamento fanerocotiledonar.

Palavras-chave: Acca sellowiana; Campomanesia guazumifolia; Campomanesia xanthocarpa; Eugenia rostrifolia.

\section{ABSTRACT}

Myrtaceae family is well represented in the flora of Rio Grande do Sul, in the Southern region of Brazil. The seed and the fruits from six trees species of this family were examined concerning their size, color, mass and water content. The species were the following: Acca sellowiana (Berg.) Burnet; Campomanesia guazumifolia (Camb.) Berg.; Campomanesia xanthocarpa Berg.; Eugenia rostrifolia Legr.; Myrcianthes pungens (Berg.) Legr and Psidium cattleyanum Sabine. The germinative behavior of the seeds was evaluated and the substratum used was autoclaved, which was placed in gerbox $(11 \mathrm{x} 11 \mathrm{~cm})$, at constant temperatures $15,20,25$ or $30^{\circ} \mathrm{C}$ or in alternate ones $15^{\circ} \mathrm{C} / 30^{\circ} \mathrm{C}$, with fourteen hours period, in the highest temperature. The experiments were also carried out in the dark. The seeds of Acca sellowiana, Myrcianthes pungens, Psidium cattleyanum showed positive photoblastic behavior. All species germinated in 90 days except Campomanesia guazumifolia which took around 150 days to germinate. The water content ranged from $9 \%$ in Campomanesia guazumifolia to $68 \%$ in Myrcianthes pungens and the seeds varied from intermediate to recalcitrant ones. The eugenoid embryos had a cryptocotylar germination, however the myrciod and the pimentoid had a fanerocotylar germination.

Key-words: Acca sellowiana; Campomanesia guazumifolia; Campomanesia xanthocarpa; Eugenia rostrifolia.

\section{INTRODUÇÃO}

No Brasil, o agronegócio é um dos setores mais competitivos da economia, produzindo em torno de $40 \%$ do produto interno bruto (Almeida, 1998). Lavouras extensivas de poucas espécies apropriam-se ano a ano de mais área e tentam manter ou aumentar a produtividade às custas de insumos, como adubos, herbicidas e outros químicos. A população perde em variabilidade de dieta alimentar e conhecimento do uso

1. Engenheira Agrônoma, Mestranda pelo Programa de Pós-Graduação em Botânica, Universidade Federal do Rio Grande do Sul, CEP 91501-970, Porto Alegre (RS). cfernandosantos@terra.com.br

2. Biólogo, Professor Titular Aposentado da Universidade Federal do Rio Grande do Sul, Caixa Postal 15015, CEP 91501-970, Porto Alegre (RS). Bolsista do CNPq. ferreira@unb.br

3. Bióloga, Professora Adjunta Aposentada da Universidade Federal do Rio Grande do Sul, CEP 91501-970, Porto Alegre (RS).meaquila@ig.com.br

Recebido para publicação em 24/04/2003 e aceito em 10/09/2004. 
de espécies nativas capazes de oferecer alternativas ricas e nutritivas. Estas espécies poderiam ser mais largamente usadas para consumo "in natura" ou para preparo de doces, geléias, sucos e sorvetes. Além de fins alimentares para o homem, a fauna aprecia muito os frutos, especialmente a avifauna.

Entre as mirtáceas, há várias espécies com valor ornamental, quer pela delicadeza da folhagem, quer pela beleza de suas flores e do colorido dos frutos. Como muitas espécies são de porte pequeno ou médio, poderiam ser usadas em jardins e outros espaços limitados. Este é um setor em franco crescimento no estado (Kämpf e Dauat, comunicação pessoal). As mirtáceas não são valorizadas no setor de reflorestamento pela sua madeira, pois esta só se presta para fabrico de pequenas peças de ferramenta ou lenha. Porém, sua importância está ligada à recuperação de áreas degradadas e ao enriquecimento de florestas secundárias (Mairesse, 1998).

No nível de pequenas e médias propriedades rurais, pode-se estabelecer uma prática voltada ao plantio de espécies nativas, ocupando áreas menos nobres da propriedade, mas assumindo importância econômica similar a outras culturas e criações (Medeiros, 1992).

A germinação de sementes é um dos pontos críticos na ontogênese de um indivíduo e das plantas como um todo. O conhecimento e a compreensão desta fase do desenvolvimento é um requerimento para a explicação da ocorrência de uma espécie numa determinada região (Áquila e Ferreira, 1984). A germinação depende de fatores internos e externos à semente, dos quais a água, a temperatura, o oxigênio e a luz são os mais importantes (Baskin e Baskin, 1998), Em solos umedecidos, a temperatura e a luz são os fatores mais importantes (Heydecker, 1997). A manipulação da temperatura e da luz pode fornecer várias informações sobre o comportamento germinativo e instalação de várias espécies (Ferreira et al., 1994). A temperatura altera a velocidade de absorção de água e das reações bioquímicas que acionam o metabolismo, transporte e ressíntese (Carvalho e Nakagawa, 1988; Bewley e Black, 1994).

O estímulo luminoso é bastante variável sobre a germinação de espécies selvagens (Mayer e Poljokoff-Mayber, 1989), por isso, exigindo informações sobre as condições ótimas de germinação (Rosa e Ferreira, 1999). Assim, as sementes foram classificadas em três grandes grupos em relação à resposta à luz: fotoblásticas positivas (que germinam só ou muito melhor na luz), fotoblásticas negativas ( em que a germinação é inibida pela luz) e as indiferentes Orozco-Segovia e Vasquez-Yanes, 1992; Takaki, 2001).

Com os objetivos de avaliar aspectos qualitativos das sementes recém beneficiadas, bem como alguns parâmetros de luz e temperatura de germinação de mirtáceas nativas do Rio Grande do Sul, é que este trabalho foi realizado.

\section{MATERIAL E MÉTODOS}

\section{Material botânico}

Frutos maduros de Acca sellowiana (Berg.) Burnet (goiabeira-serrana), Campomanesia guazumifolia (Camb.) Berg. (sete-capotes), Campomanesia xanthocarpa Berg. (guabiroba); Eugenia rostrifolia Legr.(batinga), Myrcianthes pungens (Berg.) Legr. (guabijú) e Psidium cattleyanum Sabine (araçá-vermelho) - Myrtaceae - foram coletados na região litorânea, no Planalto Médio ou na Depressão Central na primavera/verão de 2000/01 (Tabela 1). O material foi beneficiado e analisado no laboratório de Tecnologia de Sementes da Fundação Estadual de Pesquisa Agropecuária - FEPAGRO - em Porto Alegre, RS.

\section{Análise física dos frutos}

Em laboratório, analisaram-se os frutos das seis espécies identificando-se o tipo de fruto (Barroso, 1991), a coloração e o teor de umidade. Para determinar o teor de umidade (\%) dos frutos, estes foram pesados e, em seguida, dois frutos (para os que possuíam diâmetro igual ou maior que $5 \mathrm{~cm}$ ) ou cinco frutos (para os de diâmetro inferior a $5 \mathrm{~cm}$ ) (com duas repetições) foram postos em estufa a $105^{\circ} \mathrm{C} \pm 2^{\circ} \mathrm{C}$, por 24 horas. Os frutos, depois de resfriados em dissecador com sílica-gel, foram pesados de acordo com as regras para análise de sementes (Brasil, 1992). 
TABELA 1: Mirtáceas nativas pesquisadas: nomes científicos e comuns, locais e datas de coleta.

TABLE 1: Native myrtaceous: scientific and common name, place and date where the collect were made.

\begin{tabular}{|c|c|c|c|}
\hline Nome Científico & Nome Comum & $\begin{array}{l}\text { Local de Coleta } \\
\end{array}$ & Data de Coleta \\
\hline $\begin{array}{l}\text { Acca sellowiana (Berg.) } \\
\text { Burret. }\end{array}$ & Goiabeira- serrana & Litoral, área rural do Município de Maquiné & $06 / 04 / 01$ \\
\hline $\begin{array}{l}\text { Campomanesia } \\
\text { guazumifolia (Camb.) Berg. }\end{array}$ & Sete-capotes & $\begin{array}{l}\text { Planalto Médio, área rural do município de } \\
\text { Boa Vista do Cadeado }\end{array}$ & $27 / 02 / 01$ \\
\hline $\begin{array}{l}\text { Campomanesia } \\
\text { xanthocarpa Berg. }\end{array}$ & Guabirobeira & $\begin{array}{l}\text { Planalto Médio, área rural do município de } \\
\text { Boa Vista do Cadeado }\end{array}$ & $01 / 12 / 00$ \\
\hline Eugenia rostrifolia Legr. & Batinga & Litoral, área rural do município de Maquiné & $18 / 04 / 01$ \\
\hline $\begin{array}{l}\text { Myrcianthes pungens } \\
\text { (Berg.) Legr. }\end{array}$ & Guabijú & $\begin{array}{l}\text { Depressão Central, área urbana do município } \\
\text { de Viamão }\end{array}$ & $13 / 02 / 01$ \\
\hline $\begin{array}{l}\text { Psidium cattleyanum } \\
\text { Sabine. }\end{array}$ & Araçá-vermelho & $\begin{array}{l}\text { Depressão Central, área urbana do município } \\
\text { de Viamão }\end{array}$ & 07/10/00 \\
\hline
\end{tabular}

\section{Beneficiamento e análise física das sementes}

Os frutos foram despolpados sob água corrente em uma peneira. As sementes limpas foram secas por 24 horas sobre papel absorvente. Foram contabilizados o número de sementes por fruto (nunca menos do que dez frutos por espécie), sua coloração à luz solar direta e sob lupa e o peso de mil sementes, determinado com oito repetições de cem sementes (Brasil, 1992). Duas repetições de cinco gramas foram colocadas em estufa a $103^{\circ} \mathrm{C}$, por 24 horas, para determinação do grau de umidade. Todas as sementes foram analisadas topicamente quanto à presença de invasoras e danos, conforme as regras de análise de sementes (Brasil, 1992). As sementes foram secionadas, e o tipo de embrião examinado, adotando-se a classificação sugerida por Barroso (1991).

\section{Germinação}

Cem sementes foram divididas em oito subamostras, das quais quatro com 12 sementes e quatro com 13 sementes. Em cada caixa gerbox contendo $150 \mathrm{~g}$ de areia esterilizada e $20 \mathrm{ml}$ de água, foram semeadas 12 ou 13 sementes, previamente desinfestadas com hipoclorito de sódio a $1 \%$ de cloro ativo por dez minutos e enxaguadas com água estéril (Rosa e Ferreira, 1998). As placas foram tampadas, e aquelas destinadas ao tratamento sem luz foram envoltas em embalagem preta, sendo a germinação avaliada apenas no final do experimento (Andrade, 1995). As placas foram colocadas em câmaras de germinação tipo BOD, nas temperaturas constantes de $15^{\circ} \mathrm{C}, 20{ }^{\circ} \mathrm{C}, 25{ }^{\circ} \mathrm{C}$ ou $30^{\circ} \mathrm{C}$, localizadas numa sala climatizada com a temperatura ajustada para $18^{\circ} \mathrm{C} \pm 3^{\circ} \mathrm{C}$ (Ikuta e Barros, 1996). O regime de temperaturas alternantes foi de $15 / 30^{\circ} \mathrm{C}$, às $10 / 14$ horas, respectivamente. As câmaras eram iluminadas com lâmpadas fluorescentes de 20 watts (GE) super luz do dia, o que permitia um fluxo radiante de cerca de $50 \mu \mathrm{mol} \mathrm{m}^{-2} \mathrm{~s}^{-1}$. (Rosa e Ferreira, 1998). Foram consideradas germinadas as sementes que apresentaram radícula com cinco ou mais milímetros de comprimento (Andrade e Pereira, 1994), sendo as observações efetuadas diariamente.

\section{Análise de germinação e estatística}

Nos experimentos de germinação, usou-se delineamento experimental completamente casualisado. Os dados obtidos foram submetidos ao teste de homogeneidade de Bartlett, seguidos de ANOVA (Sokal e Rohlf, 1981). As médias foram comparadas pelo teste de Tukey (5\%), usando-se programa SANEST (Zonta e Machado, 1984).

O tempo médio de germinação (TM) foi calculado de acordo com Labouriau e Agudo (1987). O desvio padrão do tempo médio (S) para variabilidade dos dados e a velocidade média de germinação (VMG) utilizados foram os recomendados por Labouriau (1983), onde:

$\mathrm{TM}=€$ ni. ti $/ € n i$

Em que: $\mathrm{ni}=$ número de sementes germinadas no tempo ti (dados não acumulados); ti = tempo entre o início do experimento e a observação.

$$
\mathrm{VMG}=1 / \mathrm{TM}
$$

\section{RESULTADOS E DISCUSSÃO}

As seis espécies examinadas apresentaram frutos maduros em forma de baga, de vários subtipos (Tabela 2), variando a cor de verde-escuro, amarelada, vermelha a roxa-escuro. O teor de água dos frutos ficou entre $40 \%$ (Myrcianthes pungens) a $86 \%$ em Psidium cattleyanum. As sementes de cor amarelada ocorreram de uma por fruto (Eugenia rostrifola e Myrcianthes pungens) a 48 sementes por fruto (Acca 
sellowiana). As sementes pequenas pesaram de $0.287 \mathrm{~g}$ (Myrcianthes pungens) a $0,004 \mathrm{~g}$ (Acca sellowiana) (Tabela 2).

TABELA 2: Mirtáceas nativas do Rio Grande do Sul: características dos frutos e das sementes.

TABLE 2: Native myrtaceous from Rio Grande do Sul State: fruits and seeds characteristics.

\begin{tabular}{|c|c|c|c|c|}
\hline \multicolumn{5}{|c|}{ Características de frutos } \\
\hline Espécies & Tipo & Cor & \multicolumn{2}{|c|}{ Umidade (\%) } \\
\hline Acca sellowiana (Berg.) Burret. & $\begin{array}{c}\text { Baga } \\
\text { (Solanídio) }\end{array}$ & Verde-escura & \multicolumn{2}{|c|}{76} \\
\hline $\begin{array}{l}\text { Campomanesia guazumifolia (Camb.) } \\
\text { Berg. }\end{array}$ & $\begin{array}{c}\text { Baga } \\
\text { (Campomanesoídeo) }\end{array}$ & Verde-amarelado & \multicolumn{2}{|c|}{78} \\
\hline Campomanesia xanthocarpa Berg. & $\begin{array}{c}\text { Baga } \\
\text { (Campomanesoídeo) }\end{array}$ & Amarelo & \multicolumn{2}{|c|}{83} \\
\hline Eugenia rostrifolia Legr. & $\begin{array}{c}\text { Baga } \\
\text { (Bacáceo })\end{array}$ & Amarelo-alaranjado & \multicolumn{2}{|c|}{43} \\
\hline Myrcianthes pungens (Berg.) Legr. & $\begin{array}{c}\text { Baga } \\
\text { (Bacídio) }\end{array}$ & Roxo-escuro & \multicolumn{2}{|c|}{40} \\
\hline Psidium cattleyanum Sabine. & $\begin{array}{c}\text { Baga } \\
\text { (Solanídio) }\end{array}$ & Vermelho & \multicolumn{2}{|c|}{86} \\
\hline \multicolumn{5}{|c|}{ Características das sementes } \\
\hline Espécies & Número sementes/fruto & Cor & (PMS)g & $(\%)$ \\
\hline Acca sellowiana (Berg.) Burret. & 48 & Amarelada & 4,0 & 21 \\
\hline $\begin{array}{l}\text { Campomanesia guazumifolia (Camb.) } \\
\text { Berg. }\end{array}$ & 11 & Branco-acinzentado & 31,0 & 9 \\
\hline Campomanesia xanthocarpa Berg. & 7 & Amarelo-alaranjado & 49,0 & 33 \\
\hline Eugenia rostrifolia Legr. & 1 & Branco-acinzentado & 130,0 & 34 \\
\hline Myrcianthes pungens (Berg.) Legr. & 1 & Amarelo-alaranjado & 287,0 & 68 \\
\hline Psidium cattleyanum Sabine. & 22 & Creme & 12,0 & 17 \\
\hline
\end{tabular}

Em que: PMS $=$ peso de mil sementes.

O teor de água variou entre 9\% (Campomanesia guazumifolia) e 68 U\% (Myrcianthes pungens) esécie esta, pelo alto conteúdo de água, considerada como recalcitrante (Berjak et al., 1989). Nas sementes de Campomanesia guazumifolia e Campomanesia xanthocarpa, constatou-se a presença de infestação ou imaturidade, de forma que apenas cerca de $50 \%$ eram maduras (Santos, 2003). Como houve exame prévio à germinação, nestas espécies, usaram-se apenas aquelas sementes que aparentavam estar com embrião maduro. Nas outras espécies, $100 \%$ das sementes apresentaram-se íntegras. Este exame prévio sobre a maturação das sementes é indispensável para avaliar o lote ou amostra, podendo, muitas vezes, prejudicar os índices germinativos, caso falte seleção.

As sementes de Acca sellowiana, Campomanesia xanthocarpa, Myrcianthes pungens e Psidium cattleyanum apresentaram germinação superior a $75 \%$ em noventa dias, nas temperaturas constantes de 15 , 20,25 , e $30^{\circ} \mathrm{C}$ ou $15-30^{\circ} \mathrm{C}$ alternada (Tabela 3 ).

No escuro, a germinabilidade destas espécies foi mais baixa, revelando fotoblastia positiva, com exceção de Campomanesia xanthocarpa, que foi indiferente à presença ou ausência de luz no processo germinativo (Tabela 3). A promoção da germinação na luz é comum em sementes de plantas de ambientes abertos (Ferreira et al., 2001) e de borda de floresta com características de pioneiras como são dessas espécies. Foram consideradas como faixa de máxima germinabilidade aquelas temperaturas nas quais a germinação se manteve estatisticamente nos mesmos percentuais (Cavalcante e Perez, 1995), o que foi observado para as quatro espécies (Tabela 5). Tal comportamento indica a grande potencialidade adaptativa destas espécies, pois demonstra uma capacidade de estabelecimento maior que aquela verificada quando existe maior restrição térmica (Townsend e MacGinnies, 1972).

Eugenia rostrifolia germinou melhor no escuro, na temperatura constante de $20^{\circ} \mathrm{C}$ ou alternada 15 $30^{\circ} \mathrm{C}$, revelando uma tendência a germinar, preferencialmente, em ambientes protegidos, com pouca luz e esta filtrada pela vegetação sendo mais rica em vermelho extremo (Frankland e Taylorson, 1983). Campomanesia guazumifolia só germinou depois de noventa dias, variando entre 102 e 167 dias, tendo uma 
TABELA 3: Germinabilidade após 90 dias de sementes de mirtáceas nativas do Rio Grande do Sul.

TABLE 3: Germinability after 90 days of native myrtaceous seeds from Rio Grande do Sul State.

\begin{tabular}{|c|c|c|c|c|c|}
\hline \multirow[t]{2}{*}{ Espécies } & \multicolumn{5}{|c|}{$\operatorname{Luz}(\mathrm{G} \%)$} \\
\hline & $15^{\circ} \mathrm{C}$ & $20^{\circ} \mathrm{C}$ & $25^{\circ} \mathrm{C}$ & $30^{\circ} \mathrm{C}$ & $15-30^{\circ} \mathrm{C}$ \\
\hline \multirow[t]{2}{*}{ Acca sellowiana (Berg.) Burret. } & $89 \mathrm{a}$ & $81 \mathrm{a}$ & $83 \mathrm{a}$ & $84 \mathrm{a}$ & $76 \mathrm{a}$ \\
\hline & A & A & A & A & A \\
\hline Campomanesia guazumifolia* (Camb.) Berg. & 0 & 0 & 0 & 0 & 0 \\
\hline \multirow[t]{2}{*}{ Campomanesia xanthocarpa Berg. } & $96 \mathrm{a}$ & $100 \mathrm{a}$ & $96 \mathrm{a}$ & 93 a & 99 a \\
\hline & A & A & A & A & A \\
\hline \multirow[t]{2}{*}{ Eugenia rostrifolia Legr. } & $0 \mathrm{c}$ & $12 \mathrm{bc}$ & $37 \mathrm{a}$ & $31 \mathrm{ab}$ & $6 \mathrm{c}$ \\
\hline & $\mathrm{B}$ & B & A & A & $\mathrm{B}$ \\
\hline \multirow[t]{2}{*}{ Myrcianthes pungens (Berg.) Legr. } & - & $83 \mathrm{a}$ & $98 \mathrm{a}$ & $88 \mathrm{a}$ & $85 \mathrm{a}$ \\
\hline & & A & A & A & A \\
\hline \multirow[t]{2}{*}{ Psidium cattleyanum Sabine. } & $94 \mathrm{a}$ & $87 \mathrm{a}$ & $82 \mathrm{a}$ & $81 \mathrm{a}$ & $82 \mathrm{a}$ \\
\hline & A & A & A & A & A \\
\hline \multirow[t]{2}{*}{ Espécies } & \multicolumn{5}{|c|}{ Escuro $(\mathrm{G} \%)$} \\
\hline & $15^{\circ} \mathrm{C}$ & $20^{\circ} \mathrm{C}$ & $25^{\circ} \mathrm{C}$ & $30^{\circ} \mathrm{C}$ & $15-30^{\circ} \mathrm{C}$ \\
\hline \multirow[t]{2}{*}{ Acca sellowiana (Berg.) Burret. } & $38 \mathrm{a}$ & $24 \mathrm{~b}$ & $16 \mathrm{~b}$ & $2 \mathrm{c}$ & $48 \mathrm{a}$ \\
\hline & $\mathrm{B}$ & $\mathrm{B}$ & $\mathrm{B}$ & $\mathrm{B}$ & $\mathrm{B}$ \\
\hline Campomanesia guazumifolia* (Camb.) Berg. & 0 & 0 & 0 & 0 & 0 \\
\hline \multirow[t]{2}{*}{ Campomanesia xanthocarpa Berg. } & $82 \mathrm{a}$ & $88 \mathrm{a}$ & $93 \mathrm{a}$ & $91 \mathrm{a}$ & $91 \mathrm{a}$ \\
\hline & B & $\mathrm{B}$ & A & A & $\mathrm{B}$ \\
\hline \multirow[t]{2}{*}{ Eugenia rostrifolia Legr. } & $19 \mathrm{bc}$ & $56 \mathrm{a}$ & $37 \mathrm{ab}$ & $0 \mathrm{c}$ & $50 \mathrm{a}$ \\
\hline & A & A & A & $\mathrm{B}$ & A \\
\hline \multirow[t]{2}{*}{ Myrcianthes pungens (Berg.) Legr. } & - & $4 \mathrm{~b}$ & $31 \mathrm{a}$ & $0 \mathrm{~b}$ & $0 \mathrm{~b}$ \\
\hline & & $\mathrm{B}$ & $\mathrm{B}$ & $\mathrm{B}$ & $\mathrm{B}$ \\
\hline \multirow[t]{2}{*}{ Psidium cattleyanum Sabine. } & $13 \mathrm{~b}$ & $6 \mathrm{~b}$ & $0 \mathrm{~b}$ & $0 \mathrm{~b}$ & $37 \mathrm{a}$ \\
\hline & $\mathrm{B}$ & $\mathrm{B}$ & $\mathrm{B}$ & $\mathrm{B}$ & $\mathrm{B}$ \\
\hline
\end{tabular}

Em que: G\% = germinabilidade percentual; * = germinação ocorreu após 90 dias. Letras minúsculas iguais na linha, pó tratamento, não diferem significativamente pelo teste de Tukey a 5\%. Letras maiúsculas na linha, comparação entre temperaturas dentro dos tratamentos de luz ou de escuro pelo teste de Tukey a 5\%.

velocidade média de germinação (VMG) bem mais baixa que as demais espécies (Tabela 4). Em poucos casos o tempo médio de germinação(TM) foi menor que trinta dias (Tabela 4). Este tempo mais longo sugere uma dormência inicial pouco pronunciada, como foi encontrado para as sementes de Eugenia pyriformis uvaia (Andrade e Ferreira, 2000). Para as sementes de Eugenia rostrifolia a 20 ou $15-30^{\circ} \mathrm{C}$, o tempo médio de germinação foi bem inferior a trinta dias (Tabela 4). Estes dados devem ser examinados com reservas, já que este tempo médio foi obtido a partir de dados de germinação de poucas unidades, em alguns casos (Tabela 3), o que pode falsear a interpretação dos resultados.

TABELA 4: Análise de cinética da germinação de mirtáceas nativas do Rio Grande do Sul, em presença de luz, em 4 temperaturas constantes e uma alternada, após 90 ou 170 dias. Tempo médio (TM), velocidade média de germinação (VMG) e desvio padrão do tempo médio (entre parênteses).

TABLE 4: Germination kinetic analysis of native myrtaceous from Rio Grande do Sul State, at light in four constant temperatures and one alternated after 90 or 170 days. Mean time (TM), average germination velocity (VMG) and standard deviation of the mean time (between brachets).

\begin{tabular}{cc|c|c|c|c|c}
\hline \multirow{2}{*}{ Espécies } & \multicolumn{5}{c}{ Temperaturas $\left({ }^{\circ} \mathrm{C}\right)$} \\
\cline { 3 - 7 } & & 15 & 20 & 25 & 30 & $15-30$ \\
\hline Acca sellowiana (Berg.) Burret & $\mathrm{TM}$ & 33,08 & 25,34 & 30,83 & $20,42(8,72)$ & 26,86 \\
& & $(11,62)$ & $(10,47)$ & $(17,81)$ & $(10,33)$ \\
& VMG & 0,030 & 0,039 & 0,032 & 0,049 & 0,037 \\
\hline
\end{tabular}


TABELA 4: Continuação ...

TABLE 4: Continued ...

\begin{tabular}{|c|c|c|c|c|c|c|}
\hline \multirow{2}{*}{\multicolumn{2}{|c|}{ Espécies }} & \multicolumn{5}{|c|}{ Temperaturas $\left({ }^{\circ} \mathrm{C}\right)$} \\
\hline & & 15 & 20 & 25 & 30 & $15-30$ \\
\hline Campomanesia guazumifolia & TM 90 dias & 0 & 0 & 0 & $0 \quad 149,8$ & 0 \\
\hline \multirow[t]{3}{*}{ (Camb.) Berg. } & 170 dias & 0 & $\begin{array}{c}102,5 \\
(58,34)\end{array}$ & $\begin{array}{c}162,7 \\
(23,35)\end{array}$ & $(14,40)$ & $\begin{array}{c}167,3 \\
(22,68)\end{array}$ \\
\hline & VMG & 0 & 0 & 0 & 0,007 & 0 \\
\hline & & 0 & 0,012 & 0,006 & & 0,006 \\
\hline \multirow[t]{2}{*}{ Campomanesia xanthocarpa Berg. } & TM & $\begin{array}{c}15,88 \\
(6,35)\end{array}$ & $\begin{array}{l}17,77 \\
(7,18)\end{array}$ & $\begin{array}{c}8,65 \\
(2,23)\end{array}$ & $8,90(3,69)$ & $\begin{array}{l}12,29 \\
(3,72)\end{array}$ \\
\hline & VMG & 0,063 & 0,056 & 0,110 & 0,110 & 0,081 \\
\hline \multirow[t]{2}{*}{ Eugenia rostrifolia Legr } & TM & $\begin{array}{c}0 \\
(0)\end{array}$ & $\begin{array}{c}17,53 \\
(16,10)\end{array}$ & $\begin{array}{c}55,66 \\
(11,19)\end{array}$ & $\begin{array}{c}54,96 \\
(19,17)\end{array}$ & $\begin{array}{c}18,59 \\
(11,03)\end{array}$ \\
\hline & VMG & 0 & 0,057 & 0,018 & 0,018 & 0,054 \\
\hline \multirow[t]{2}{*}{ Myrcianthes pungens (Berg.) Legr. } & TM & - & $\begin{array}{c}44,38 \\
(12,40)\end{array}$ & $\begin{array}{l}20,52 \\
(3,50)\end{array}$ & $\begin{array}{c}41,75 \\
(10,53)\end{array}$ & $\begin{array}{c}37,81 \\
(16,00)\end{array}$ \\
\hline & VMG & - & 0,022 & 0,049 & 0,024 & 0,026 \\
\hline \multirow[t]{2}{*}{ Psidium cattleyanum Sabine } & TM & $\begin{array}{c}36,86 \\
(2,69)\end{array}$ & $\begin{array}{l}42,78 \\
(9,42)\end{array}$ & $\begin{array}{l}44,55 \\
(5,40)\end{array}$ & $44,05(6,71)$ & $\begin{array}{l}32,91 \\
(4,61)\end{array}$ \\
\hline & VMG & 0,027 & 0,023 & 0,022 & 0,023 & 0,030 \\
\hline
\end{tabular}

Os embriões, importantes para taxonomia de Myrtaceae (Barroso, 1991), apresentaram-se do tipo mircióide em Acca sellowiana, do tipo pimentoide em Campomanesia guazumifolia, Campomanesia xanthocarpa e Psidium cattleyanum, e do tipo eugenoide em Eugenia rostrifolia e Myrcianthes pungens (Tabela 5). Nos dois primeiros tipos, a germinação foi fanerocotiledonar, funcionando os cotilédones como as primeiras folhas fotossintetizantes ( Boesewinkel e Bouman, 1995), enquanto no tipo eugenoide foi criptocoliledonar (Tabela 5). Isto significa que o comportamento germinativo está correlacionado ao tipo de embrião, nesta família.

TABELA 5: Germinação de mirtáceas nativas do Rio Grande do Sul: faixa de máxima germinabilidade, fotoblastismo, tipos: de germinação das sementes e de embrião.

TABLE 5: Native myrtaceous seed germination: optimum germination temperature range, photoblastism, shape of embryos.

\begin{tabular}{|c|c|c|c|c|}
\hline Espécie & $\begin{array}{c}\text { Faixa de Máxima } \\
\text { Germinabilidade }\end{array}$ & Fotoblastismo & $\begin{array}{c}\text { Tipo de } \\
\text { Germinação }\end{array}$ & $\begin{array}{l}\text { Tipo de } \\
\text { Embrião }\end{array}$ \\
\hline $\begin{array}{l}\text { Acca sellowiana (Berg.) } \\
\text { Burret. }\end{array}$ & $\begin{array}{l}15^{\circ} \mathrm{C} \text { a } 30^{\circ} \mathrm{C} \text { constante } \\
\text { e } 15-30^{\circ} \mathrm{C} \text { alternada }\end{array}$ & $\begin{array}{l}\text { Fotoblástica Positiva ou } \\
\text { Fotoblástica Positiva Relativa }\end{array}$ & $\begin{array}{l}\text { Epígea } \\
\text { Fanerocotiledonar }\end{array}$ & mircióide \\
\hline Campomanesia & & & Epígea & pimentoide \\
\hline guazumifolia (Camb.) & - & - & Fanerocotiledonar & \\
\hline
\end{tabular}

Berg.

Campomanesia xanthocarpa Berg. Eugenia rostrifolia Legr.

Myrcianthes pungens

(Berg.) Legr.

Psidium cattleyanum

Sabine. $15^{\circ} \mathrm{C}$ a $30^{\circ} \mathrm{C}$ constante Afotoblástica ou Fotoblástica e $15-30^{\circ} \mathrm{C}$ alternada Positiva Relativa $20^{\circ} \mathrm{C}$ a $30^{\circ} \mathrm{C}$ constante Termofotoblástica pinentóide

Epígea

Fanerocotiledonar

Hipógea

Criptocotiledonar

eugenóide

eugenóide

Hipógea

Criptocotiledonar

Epígea

Fanerocotiledonar

pimentóide e $15-30^{\circ} \mathrm{C}$ alternada

Em que: Embrião mircióide $=($ Barroso, 1991) globoso ou elipsóide, com cotilédones foliáceos ou membranáceos. Embrião pimentóide $=($ Barroso, 1991): crasso, enrolado, cotilédones rudimentares ou pouco desenvolvidos. Embrião eugenóide $=($ Barroso, 1991): globoso a ovóide, crasso, cotilédones pouco diferenciados e soldados. 


\section{CONCLUSÕES}

Os frutos das seis espécies são bagas de cor variável na maturidade.

As sementes das seis mirtáceas examinadas são pequenas, com conteúdo de água entre 9 e $68 \%$.

As sementes apresentaram-se como fotoblásticas positivas em Acca sellowiana, Campomanesia guazumifolia, Myrcianthes pungens, Psidium cattleyanum, com altos índices germinativos entre 15 e $30^{\circ} \mathrm{C}$.

Os embriões eugenóides apresentam germinação tipo criptocotiledonar, enquanto os tipos mircióide e pimentóide mostram comportamento fanerocotiledonar.

\section{AGRADECIMENTOS}

À doutora Rosa Neli Bento Andrade, pelo auxílio nas fases iniciais deste trabalho. Ao CNPq, pela bolsa de pós-graduação à primeira autora e pela bolsa de produtividade à AG Ferreira.

\section{REFERÊNCIAS BIBLIOGRÁFICAS}

ALMEIDA, F.J. Marketing de sementes : curso de tecnologia de sementes, módulo UFPel/ABEAS. Brasília (DF), 1998.

ANDRADE, A.C. S. Efeito da luz e da temperatura na germinação de Leandra breviflora Cogn., Tibouchina benthamiana Cogn., T. grandiflora e T.moricandiana (DC) Baill. (Melastomataceae) Revista Brasileira de Sementes, v.17, n.1, p. 29-35, 1995.

ANDRADE, A.C.S.; PEREIRA, T.S. Efeito do substrato e da temperatura na germinação e no vigor de sementes de cedro - Cedrela odorata L. (Meliaceae). Revista Brasileira de sementes, v.16, n.1, p. 34-40, 1994.

ANDRADE, R.N.B.; FERREIRA, A.G. Germinação e armazenamento de sementes de uvaia (Eugenia pyriformis Camb.) -Myrtaceae. Revista Brasileira de Sementes, v.22, n.2, p. 118-125, 2000.

AQUILA, M.E.A.; FERREIRA, A.G. Germinação de sementes escarificadas de Araucaria angustifolia em solo. Ciência e Cultura, v.36, n.9, p. 1583-1590, 1984.

BARROSO, G. M.. Sistemática de Angiospermas do Brasil, Viçosa : Ed. Imprensa Universitaria, 1991. v.2.

BASKIN, C.C.; BASKIN, J.M. Seeds: ecology, biogeography, and evolution of dormancy and germination. New York : Academic Press, 1998.

BERJAK, P.; FARRANT, J.M.; PAMMENTER, N.W. The basis of recalcitrant seed behaviour: cell biology of the homoiohydrous seed condition. In: TAYLORSON, R.B. (Ed.). Recent Advances in the development and germination seeds. New York : Plenum Press, 1989. p. 89-108.

BEWLEY, J.D.; BLACK, M. Seeds: physiology of development and germination. New York : Plenum Press, 1994.

BOESEWINKEL, F.D., BOUMAN, F. Seed morphology and development. In: KIGEL, J.; GALILI, G. Seed development and germination. New York : Marcel Dekker ,1995. p. 1-24.

BRASIL. Ministério da Agricultura. Regras de análise de sementes. Brasilia, 1992.

CARVALHO, N.M., NAKAGAWA, J. Sementes: ciência, tecnologia e produção Campinas: Fundação Cargill, 1988.

CAVALCANTE, A.M.B., PEREZ, S.C.J.G.A. Efeitos da temperatura sobre a germinação de sementes de Leucaena leucocephala (Lam) de Wit . Revista Brasileira de Sementes, v.17, n.1, p. 1-8, 1995.

FERREIRA, A.G.; BORGHETTI, F.; SCHWAMBACK, L.; SILVEIRA, T.S. Efeito do substrato e pH no desenvolvimento inicial de plantas. Caderno de Pesquisa Serie Botânica, Santa Cruz do Sul, v.6, n.1, p. 13-23, 1994.

FERREIRA, A.G.; CASSOL, B.; ROSA, S.G.T.; SILVEIRA, T.S.; STIVAL, A.L.; SILVA, A.A. Germinação de sementes de Asteraceae nativas. Acta Botanica Brasilica, v.15, n.2, p. 231-242, 2001.

HEYDECKER, W. Stress and seed germination: na agronomic view. In: KHAN, A.(Ed.). The physiology and biochemistry of seed dormancy and germination. Amsterdam : Elsevier, 1997.

IKUTA, A.R. Y., BARROS, I. B. I. Influência da temperatura e da luz sobre a germinação de marcela (Achyrocline satureioides). Pesquisa Agropecuária Brasileira, v.31, n.12, p. 859-862, 1996.

KAMPF, A. N. Produção comercial de plantas ornamentais. Guaiba: Ed Agropecuária, 2000. 
LABOURIAU, L.G. A germinação das sementes. Washington: OEA, 1983. 174 p.

LABOURIAU, L.G.; AGUDOM. On the physiology of seed germination in Salvia hispanica L. II. Light-temperature interactions: preliminary results. Anais da Academia Brasileira de Ciências ,v.59, n.1 p. 37-56, 1987.

MAIRESSE, L.A. da S. Técnicas de biotecnologia como auxiliar no melhoramento genético de espécies florestais. In : REUNIAO TECNICA DE FRUTICULTURA, 5, 1998, Veranopolis. Anais... Veranópolis, 1998.

MARCHIORI, J.N.C.; SOBRAL, M. Dendrologia das Angiospermas - Myrtales. Santa Maria :Ed. UFSM, 1997.

MAYER, A.M. \& POLJAKOFF-MAYBER, A. The germination of seeds Pergamon Press (Oxford), 1989.

MEDEIROS, J.D. Reflorestar é Preservar. Ed. Setor de comunicação social/departamento de fumo da Souza Cruz. Florianópolis, 1992.

OROZCO-SEGOVIA, A.\& VASQUEZ-YANES, C. Los sentidos de las plantas: La sensibilidad de las semillas a la luz. Ciencia v.43 p. 399-411, 1992.

ROSA, S. G. T. \& FERREIRA, A.G. Germinação de sementes de espécies medicinais do Rio Grande do Sul: Bromelia antiacantha Bert., Cuphea carthagenesis (Jacq.) Mccbride e Talinum patens (Jacq.) Willdenow Acta Botanica Brasilica v.12 n.3 p.: 515-522, 1998.

ROSA, S.G. T. \& FERREIRA, A.G. Germination of medicinal plant: Smilax campestris Griseb (Salsaparrilha) Acta Horticulturae v.502 p. 105-111, 1999.

SANTOS, C.M.R. Myrtaceae -análises morfológicas e do efeito da temperatura e da luz na germinação de sementes de espécies nativas do Rio Grande do Sul. Porto , UFRGS, 2003. Dissertação (Mestrado em Botânica), Universidade Federal do Rio Grande do Sul, 2003.

SOKAL, R. \& ROHLF, F.L. Biometry. W.H. Freeman, San Francisco, 1981.

TAKAKI, M. New proposal of classification of seeds based on forms of phytochrome instead of photoblastism. Revista Brasileira de Fisiologia Vegetal. v.13 n.1 p. 103-107, 2001.

TOWNSEND, C.E. \& MACGINNIES, W.J. Mechanical scarification of Cicer Milkvetch ( Astragalus cicer L.) seed. Crop Science v.12: p.392-394, 1972.

ZONTA, E. P. \& MACHADO, A.A. SANEST -Sistema de Análise estatística para microcomputadores. Universidade. Federal de Pelotas. Pelotas. 190p. 1984. 